\title{
Nancy Y. Wu (ed.) \\ Ad Quadratum: The Practical Application of Geometry in Medieval Architecture
}

\author{
Ashgate Press, 2003 \\ Reviewed by Maria Teresa Bartoli
}

Ad Quadratum is the proceedings of an international congress on medieval studies. As the preface by editor Nancy Wu and W.W. Clark makes clear, the intention of this volume is to discuss the relationship between geometry and medieval architecture from the standpoint of operational geometry. The book presents essays by different authors, each one examining medieval monuments from different personal approaches and different points of view. Nevertheless, all share the same purpose: they aim at finding the "system" with which the building was laid out, basing their analysis on geometry and metrology.

The lucid and sharp introduction by Eric C. Fernie reveals the common nature of all the articles. He points out the true goal of the volume, which is to define the actual "state of the art", in medieval architecture studies. Fernie's opinion is that the development of these studies is inadequate, mainly because of the defensive attitude of investigators, who are not open to the idea of discussing and modifying their theories.

Describing the investigators' analysis and the "systems" they propose (and also condemning some inconsistent approaches), Ernie outlines some basic points in this field of studies, which are the need for measured surveys; the issues about tolerance of measurements; and the effect of digital representation (CAD) upon the analogical pattern-analysis of architectural buildings. $\mathrm{He}$ discusses some of the most frequent ambiguities, resulting from current prejudices, and gives the basis of a sort of "manifesto" for the study of medieval architecture.

The "systems" as described in the various articles testify to the difficulties inherent to the subject. In fact, some of the systems proposed are contradictory, while being neither completely right nor completely false. That is the case of the analyses of Marie-Thérèse Zenner and James Addiss, both of which are dedicated to the St. Etienne in Never. Zenner brings out a very complex and farraginous hypothetical geometrical layout, reconstructing the whole plan of the church from only three measures, which are derived from three heights. The drawing she contrives appears to be brilliant, but not very reliable; the discussion about the value of the measure unit does not fulfil expectations, even if some insights into geometrical methods are sharp. Addiss's interpretation seems to fit more closely to the acknowledged character of Gothic architecture, even if he admits that the results of his analysis are not at all exhaustive. His investigations about the unit of measure of the original medieval design are very convincing.

Taken as a whole, this collection of articles "provide an excellent cross-section" of current progress in the study of medieval architecture. Some of them approach architecture by focusing only on the monuments and not on the mind of the builders; hence the interpretation they propose does not seem to fit to the forma mentis of the medieval architect as it appears from literary and documentary evidences. On the other hand, some other papers try to get closer to the medieval mind in order to understand the real problems of the ancient builders. Stephen Murray 
discusses the possible presence of two units of length, suggested by some evidences coming from the dimensions of the building that he studies, the Cathedral of Amiens, and supported by literary sources. Michael T. Davis analyses the full-scale project drawings laid out on the choir terrace of Clermont Cathedral of Notre Dame. The significant study of Alpay Özdural on the church of St. George in Famagusta is very convincing: the geometrical and metrological analysis, founded on a historical basis and congruent arguments, lead the author to unexpected conclusions about the presence in Gothic architecture of musical consonances (through ratios between pairs of Pythagorean and Platonic numbers).

A final observation: some of the articles are difficult to read and to understand because of the lack of drawings. Some of the theories proposed, even if correct, have neither a graphic demonstration nor a drawn illustration, and are therefore difficult to share. In a standard book size, it is not easy to publish consistent results related to building analysis by the means of geometry and metrology. In the future, a major challenge probably should be to find a new efficient description system, either through drawing and/or writing. Since, according to archaeologists, buildings such as Greek temples were described by their architects through lists of numbers and measures rather than by drawings, and since Gothic monuments reveal an extraordinary metric determination, proposed "description systems" ought to be based on lists of survey measures, revealing the organic structures able to encompass or to explain most of these measures, major and minor.

\section{About the Reviewer}

Architect Maria Teresa Bartoli is Professore straordinario of Architectural Surveying since 2002 at the Faculty of Architecture in Florence, where she has been working since 1983, first as a ricercatore, then as Professore associato teaching drawing, surveying and geometry for architects. She has taken part (as a member of the team or as the leader) in the survey of important monuments in Florence such as Palazzo Strozzi, Palazzo Medici, Palazzo Vecchio, the Convent of Carmine, and Villa Medici, on behalf of the Public Administration. Her research fields include: the history of Renaissance perspective; the links between architecture and geometry; metrology and history of geometrical paradigms in architecture. Since 1973 she has published many articles and essays in specialized reviews, and has been a speaker at many international meetings. In 1994 she was invited by the Dibner Institute for the Science and Technology in Cambridge, Massachusetts, as speaker in a workshop on Renaissance Perspective. Her most representative publication is the volume Le ragioni geometriche del segno architettonico (Florence: Alinea, 1997). Recent publications include: "Un laboratorio dell'architettura gotica: Firenze, la città, le mura, il Palazzo" in Città, Architettura, le matrici di Arnolfo, ed. M.T.Bartoli, S. Bertocci (Florence: Edifir, 2004); "L'architetto di Palazzo Medici-2 in Firenze Architettura, 1 and 2 (2002); "Il disegno come conoscenza dell'Architettura", in the biennial periodical of the Dipartimento di Progettazione dell'Architettura, pp. 4-13. She presented "The Sequence of Fibonacci and the Palazzo della Signoria in Florence"at the Nexus 2004 conference in Mexico City. 